\title{
Research on Farmers' Skill Training Mode of "Straight across Area" on Targeted Poverty Reduction in Yunnan
}

\author{
Wen Zheng \\ Yunnan University of TCM \\ Kunming Yunnan 650500, China \\ Email: zhengwen07@126.com
}

\author{
Yuanlin Hu \\ Faculty of Management and Economics, \\ Kunming University of Science and Technology \\ Kunming Yunnan 650093, China \\ Email: 494674978@qq.com
}

\author{
Zhiqiang Mao* \\ Yunnan University of TCM, \\ Kunming Yunnan 650500, China \\ Email: 823172115@qq.com
}

\begin{abstract}
The purpose of this study is to understand the status of skills training model of "straight across area" of Yunnan nationality. Our program adopts field investigation, expert interview investigation, qualitative analysis and quantitative analysis. The results suggest that the training model of "straight across areas" in Yunnan nationality is characterized by diversity, but there are also some disadvantages such as the weak universality and excessive dependence on the government. Therefore, it is necessary to further explore the training model of farmers' skills suitable for "straight across areas".
\end{abstract}

Keywords-Targeted poverty reduction; Yunnan "straight"; Farmers skills training mode

\section{INTRODUCTION}

In the early 1950s, the Communist Party of China has adopted a special "direct transition" approach to the areas inhabited by about 660,000 ethnic groups such as Jingpo which is still at the end of the primitive society or has entered a class society, but the class differentiation is not obvious, the land ownership is not concentrated, and the level of productivity is low in Yunnan Province and some of the Lahu, Hani and Yao ethnic groups to achieve a historic leap. These areas are called ethnic "direct transition areas." Referred to as "straight through the area"[1].After more than 60 years of development, the economy and society of Yunnan's ethnic groups have undergone earth-shaking changes, basically solving the problem of food and clothing, but compared with other parts of Yunnan Province, this level of development is low-level, and the poverty problem is serious. The formation of a huge "scissors difference" has become a prominent issue affecting Yunnan Province to achieve the goal of building a well-off society in an all-round way. How to deal with the unbalanced development of Yunnan nationality has become an important national problem that needs to be solved.
Poverty alleviation first helps wisdom. Education must be brought into play to help the poor in order to eliminate the poverty problem of Yunnan nationality. At present, in the practice of "straight through the area" of the Yunnan nationality to carry out precise poverty alleviation, some methods for training farmers 'skills have emerged. Some are individual, accidental, and some have risen to the mode level. It is of great practical significance to explore and sum up the training mode of peasant skills emerging from practice, analyze the basic experience and main problems, and put forward corresponding countermeasures and suggestions to promote the training of peasant skills of Yunnan nationality.

\section{TYPE OF TYPICAL TRAINING MODEL OF "STRAIGHT ACROSS AREA" IN YUNNAN NATIONALITY}

\section{A. The "Party Branch + Leading Enterprise + Farmer" Government Leading Farmer Skills Training Model in Xiangyun County Yi nationality of Dali Prefecture[2]}

Xiaozhuangzi Village in Dongshan Township was once one of the poorest villages in Xiangyun County, Dali Prefecture, Yunnan Province. In view of this current situation, xiangyun county party branch summed up the "party branch + leading enterprise + farmer" training model suitable for xiaozhuangzi village in the practice of precision poverty alleviation since 2016. This model gives full play to the organizational leadership role of the Party branches at the grassroots level in providing targeted poverty alleviation, setting up a mechanism for linking the interests of poor households with leading enterprises in the construction of file and card construction, as well as training and support, Effectively promoting the industrial development of Lisu settlements in Dali Prefecture, Drivening the Lisu community to increase income and remove poverty., farmers are trained in the secondary industry and the tertiary industry through leading 
enterprises on the basis of using modern science and technology to transform the primary industry.

\section{B. The Leading Industry Propulsion Training Model of "Company + Base + Agricultural Production + Farmers" in Jiangcheng Hani and Yi Autonomous Prefecture of Honghe Prefecture}

Hani and Yi Autonomous County of Jiangcheng is located in the southern part of Yunnan Province and is affiliated with Honghe Prefecture of Yunnan Province.The Ethnic minorities of Hani, Yi, Yi, Yao, and Lahu ethnic groups in the county are living peoples.

The county trained farmers in the "straight area" around the leading industries and explored the "company + base + agricultural + farmer" training model in the practice of precision poverty alleviation. The mode of operation is: leading agricultural enterprises have selectively organized agricultural experts and scientific and technical personnel to train farmers in planting industries according to the actual conditions of nature, humanities, climate, transportation, development projects, and industrial advantages of the "straight across the area" with the aim of targeted poverty alleviation in combination with the agricultural season; establishing industrial associations or farmers 'cooperatives and other rural economic cooperation organizations to provide training on practical techniques, laws and regulations, and cooperative business concepts, so as to help farmers run their own businesses, manage and train themselves; Developing entrepreneurship training to help farmers with entrepreneurial aspirations and qualifications to establish enterprises suitable for local development; More farmers are encouraged to engage in the production and operation of secondary and tertiary industries, and targeted training is provided to farmers on the basis of transforming primary industries with modern science and technology; Leading agricultural enterprises set up training centers, carried out on-site practical training in enterprises, and worked hard to improve the level of practice of farmers who "went straight to the area".

\section{C. "Media + Government + School + Enterprise" Vocational Education Cultivation Model in Fugong County, Nujiang}

Fugong County of Nujiang Prefecture is a multi-ethnic border area. There are "straight ethnic groups" such as the $\mathrm{Nu}$ and Dai ethnic groups in the territory. The problem of poverty is serious and it is a key poor area in the country. The county trained farmers in the "straight area" around the leading industries and explored the "company + base + agricultural + farmer" training model in the practice of precision poverty alleviation. Themodel of "media + government + school + enterprise" has been formed to work together to promote the training model of precision poverty alleviation in vocational education in the practice of precision poverty alleviation[3]. Led by the media, the government, schools, and enterprises cooperated with the media to publicize to the masses the Party's major principles and policies for poverty alleviation and development. Vocational and technical schools took on the heavy responsibility of continuing the education of high school graduates at the beginning, and the government coordinated resources to set up a platform for poverty alleviation. We will do a good job in promoting poverty alleviation through vocational education, support the innovative practices of rural education in enterprises and institutions, and actively carry out practical and technical training.

\section{Service model of poverty alleviation workstation for academicians in Lancang Lahu Autonomous County of Puer City}

The Chinese Academy of Engineering has launched a special campaign to fight poverty jointly with the Yunnan Agricultural University Academy of Sciences in order to improve farmers 'agricultural production skills Since 2015, which is ledded by Academician Zhuyouyong, The Chinese Academy of Engineering establishes an expert poverty alleviation workstation and an academician expert consultation service station, and sets up a targeted demonstration area to help Lancang County to build an accurate poverty alleviation demonstration area. Academician Zhuyouyong's team explored the training model of "Academician + Agricultural Science and Technology Demonstration Park + Farmer" after many practices and explorations[4]. The main body of the training is experts and academicians. The training target is poor farmers in the "straight area" covered by the poverty alleviation work station. The training content is practical agricultural technology implemented around scientific research projects. The purpose of training is to rely on scientific and technological precision to alleviate poverty. The scientific breeding carried out by the academician's expert poverty alleviation work station to the Yunshan Village Artemisia daba(Lahu ethnic area) includes a demonstration project for piglets and chicken seedlings, a winter potato planting of 100 acres, a winter vegetable planting of 50 acres, and a winter fresh grape planting of 15 acres., Linxia 37 experiment and other planting demonstration projects at present; Quality training includes quality improvement projects such as farmer training, training of leaders to become rich, and development of party activists and party members.

\section{CHARACTERISTICS OF THE EXISTING TYPICAL TRAINING} MODEL OF FARMERS 'SKILLS IN "STRAIGHT ACROSS AREAS" OF YUNNAN NATIONALITY

\section{A. Aiming at precision poverty alleviation with the goal of building a moderately prosperous society in an all-round way}

The skills training model of the "straight across the region" of the ethnic group in Yunnan was formed under the vision of precise poverty alleviation. The goal of the model is to build a moderately prosperous society in an all-round way, and to promote the increase of farmers 'income and the large-scale, industrialized and efficient development of agriculture. It is characterized by paying more attention to the cultivation of farmers 'main body ability and people's professional survival ability, paying attention to the improvement of farmers' cultural literacy, spiritual enjoyment, and quality of life, reducing urban and rural cultural differences, environmental differences, and differences in tastes, and promoting urban and rural integration. 


\section{B. The training content is comprehensive with people's livelihood as the focus}

The skills training for farmers of the ethnic groups of Yunnan including farming, animal husbandry, fishing, forestry and other agricultural techniques. It also includes nonagricultural technologies such as machinery, transportation, construction, catering, home appliances, communications, clothing, home economics, beauty salons, tourism, and processing of agricultural products, indicating that the skills training of farmers in Yunnan's "straight area" has covered the first, second, and third industries. Thus, it has expanded the vision of farmers, strengthened the competitiveness of farmers in employment, and paid serious attention to the sustainable development of people who are people-oriented and focus on people's livelihood.

\section{Train the whole families of entire village for the "straight across the area" mode}

The training target is mainly the cadres of the Yunnan ethnic "straight district" village and the peasants. There are no restrictions on the number, age, and academic qualifications of each class. We will implement well-targeted support programs such as "one-family policy" and "one-district policy", enhance our ability to develop ourselves through skills training, and promote poverty alleviation in whole villages and villages.

\section{The formation of a diversified training system leading by government}

The training of farmers 'skills for the ethnic groups of Yunnan has been transformed from unilateral organization and training of government departments into a new mechanism of government-led, group participation, social donation and pluralistic interaction. Thus formed the whole society to pay attention to the ethnic "straight across the area" farmers targeted poverty alleviation, extensive participation in training farmers this system engineering pattern. In addition, with the advance of the targeted poverty alleviation work, the poverty alleviation task force "hanging, contracting and helping" has played a great role in the training of farmers.

\section{E. Combines "Imported" with "go out"}

According to the actual development of the industry and the training needs of farmers, the "go out" and "please come in" combined training methods. In terms of "going out", it is possible to organize and select village cadres who "go straight through the area", train key teachers for farmers, and raise energy people in rural areas to go out of the house to visit and study in industrially developed areas to broaden their horizons. As for "please come in", the main way to send training to the door, send skills to hand, face-to-face teaching.

\section{THE PROBlem OF FARMERS 'SKILlS TRAINING IN THE EXISTING POVERTY ALLEVIATION MODEL OF "STRAIGHT ACROSS THE AREA" OF YUNNAN ETHNIC GROUP}

\section{A. Lack of systematic theoretical guidance on skills training for farmers}

The theoretical research of "straight across the area" farmers 'skills training in Yunnan lags behind practice. There have been few systematic studies on the skills training of Yunnan ethnic "straight" farmers so far. The research on the elements of the "direct training" of farmers 'skills training in the new period, especially the objectives, contents, characteristics, modes, methods, and evaluation standards of the training teaching system, is still very unsystematic. The weakness of theoretical research inevitably leads to the difficulty of giving full play to the guidance of peasant skills training in "straight areas" of ethnic groups.

\section{B. The existing model is difficult to undertake the task of precision poverty alleviation}

It is difficult to obtain good results by hiring experts and technical personnel from the relevant parties to organize training courses from the point of view of the organization of training; The mass culture quality is low judging from the target of the training due to the serious lack of investment in education of ethnic "straight across the area" [5]; Some of the technical types or content of the training are not needed by farmers, some of the training was the latest research by experts and technicians and was difficult for farmers to understand from the content of the training; From the point of view of training time, some training can only be explained by theory because of time, and it is difficult for farmers to truly master and understand practical technologies.

\section{The universality of the model is not strong}

The Yunnan ethnic "straight area" is distributed in Xishuangbanna, Nujiang, Honghe, Dehong, Baoshan, Yuxi, Lijiang and other cities. The economic and social development levels and agricultural production conditions are different. The demand for science and technology and the emphasis on training of farmers in the "straight across areas" of the ethnic group have their own emphasis, which makes the skills training models of farmers in different regions not compatible with each other and universal. The model of success in one place does not necessarily apply in another.

\section{COUNTERMEASURES AND RECOMMENDATIONS}

\section{A. Strengthening the Research on the Theory of Skills Training for Peasants in Yunnan Nationality}

First, the relevant government departments at all levels should understand the necessity of the theoretical study of peasant skills training from the perspective of solving the problem of "agriculture, rural areas and farmers", which is the top priority of the Party's work, and truly attach importance to the research work on peasant skills training in Yunnan. Second, the relevant functional departments of the governments at all levels should fully mobilize the enthusiasm of all parties, 
gradually build a stable research team on peasant training theory, and provide intellectual support for the training of farmers 'skills in "straight areas".

\section{B. Continuing to adopt the "government-led" model}

It is not only conducive to bring into play the advantages of the government in the allocation of funds and resources, and macro-control. Moreover, it has wide coverage, strong security and strong support, and can form a huge push effect judging from the characteristics of the government-led type,. It applies to any area where the ethnic group "passes through the area". Therefore, in the case of the low level of productivity of the ethnic "straight across the area", the government-led training model should continue to be fully utilized to ensure the effective implementation of farmers 'training projects.

\section{Choosing the appropriate mode according to the actual situation of Yunnan nationality "straight across the area"}

First, different economic levels choose different complementary models. Due to the rapid economic development, it is possible to rely on industry to feed agriculture, and the training of farmers should also focus on "order training In Yuxi, Dali, Lijiang, Xishuangbanna, Baoshan and other relatively developed ethnic groups, "straight areas",. It is done through market-oriented operations. The training mode of vocational farmers in this area should choose the industrial promotion or cooperative organization mode that is not dominated by the government and has a high degree of market-oriented operation.

The second is to choose different complementary modes according to resource endowment. Agricultural resource endowments mainly include arable land, water resources, topography, climate, and the skills of employees[6]. The selection of skills training mode of "straight across area" of Yunnan nationality must combine the above factors to carry out reasonable planning and design. The government and enterprises are chosen to cooperate with the type of training model to achieve the training of new professional farmers in this industry on the basis of high specialization, so as to facilitate the development of a multifunctional modern agricultural industry system.

\section{CONCLUSION}

There are several types of farmers 'skills training modes in Yunnan "straight through the area", such as government-led category, leading industry promotion category, vocational education training category, expert poverty alleviation workstation service category, etc.. Each model must have its own characteristics, and there are also shortcomings such as the lack of systematic theoretical guidance and the lack of universality of the model. According to the actual choice of suitable mode in Yunnan nationality "straight across the area".

\section{REFERENCES}

[1] Wang Yuanfu. Survey on the economic and social development of the "straight area" of Yunnan nationality[J] .. Yunnan Social Science, 2007,(01):84 -88.

[2] Hujianghong. Zhangfan.. Dali "Party branch + leading enterprise + farmer" poverty alleviation model investigation[N] .. Yunnan Daily, February 3, 2017.

[3] Xingquan. Yunbao Group held a symposium on "Vocational Education and Poverty Alleviation Skills Xingjia Fugong Hope Action" to explore the "Media + Government + School + Enterprise" education poverty alleviation model[ N] .. Yunnan Network, 2016-2017 -06.

[4] Wen Suwei. On Development Talk about Innovation and Contribution [N] .. People's Daily, 2018-03-14.

[5] Liuwenguang. An Analysis of the Obstacles to Economic and Social Development of "Straightening the Nation"-Taking Yunnan "Straightening the Nation" as an Example[J] .. Frontiers, 2010,(13): 133137.

[6] Zhang Panchun. Resource endowment and agricultural modernization path selection: lessons learned from foreign countries[J] .. Jiangsu Agricultural Science, 2017, 45(03): 250-254. 